\title{
LOW COST TECHNIQUES FOR THE DIGITAL SURVEY OF A MINOAN ARCHITECTURE IN THE ARCHEOLOGICAL SITE OF PHAISTOS (CRETE)
}

\author{
D. Aiello ${ }^{1}$, F. Buscemi ${ }^{2}$, G. D'Agostino ${ }^{1, *}$, M. Galizia ${ }^{1}$, P. Militello ${ }^{3}$, C. Santagati ${ }^{1}$ \\ ${ }^{1}$ University of Catania, Department of Civil Engineering and Architecture, Italy - \\ (damianoaiello, graziana.dagostino)@gmail.com, (mgalizia, csanta)@dau.unict.it \\ ${ }^{2}$ CNR-IBAM, Catania, Italy - francesca.buscemi@cnr.it \\ ${ }^{3}$ University of Catania, Department of Humanities, Italy - milipi@unict.it
}

\section{Commission II}

KEY WORDS: Fisheye, Photogrammetry, Narrow Spaces, Archaeology, Digital Survey, Laser Scanner, GoPro

\begin{abstract}
:
The paper shows the results of an experimentation on the use of low cost tools such as action cameras for the photogrammetric surveying of relevant archaeological sites characterized by the presence of narrow and complex rooms. The archaeological site chosen for this experimentation is the South-Western Quarter, also known as Quartiere Levi, of the Minoan Palace of Phaistos (Crete), one of only two cases of buildings surviving up to the third floor in the Aegean world. The research foresaw the setting up of a pipeline aimed at obtaining a complete scaled, photorealistic and navigable 3D model, with a considerable economy in terms of work time and number of photographs. For this purpose, many efforts have been paid on solving all the issues related to the complexity of the site and on comparing the performances of traditional (Canon EOS 70D) and action (GoPro Black Hero 6) cameras as well as of two of the current most used software in the field.
\end{abstract}

\section{INTRODUCTION}

Digital survey of archaeological sites is particularly complex, both from a morphological and environmental point of view. Archaeological areas are characterized by highly irregular volumes and surfaces, unclear, narrow or inaccessible edges, and are affected by disturbing lighting conditions (e.g. shadows and false-colours determined by the structures that cover them, etc.).

In this context, it is possible that very effective instruments such as laser scanners (LS) do not guarantee adequate performance. Furthermore, in case of great complexity of the areas to be surveyed (for example layered sites affected by earthquakes), other issues should be considered: technical, such as the overlapping between the LS scans; economic, in terms of money and time expenditure (essential in archaeology due to the scarcity of available resources); practical, concerning permissions issued by local authorities to survey the site and to climb on ancient walls and structures. Quite the opposite, automatic photogrammetry, can be much more suitable for this type of survey, because of the manageability and the low cost of the cameras.

This paper describes the use of the Structure from Motion methodology through an action camera (GoPro Black Hero 6) for the acquisition of an archaeological site, whose dataset was compared with the one of a traditional camera (Canon EOS 70D).

The archaeological site chosen for this experimentation is the South-West Quarter, also known as Quartiere Levi, of the Minoan Palace of Phaistos (Crete).

The digital survey of Quartiere Levi, conducted in 2019, constituted a continuation and a development of a first laser scanning survey carried out in 2014 , which produced a quite unsatisfactory result. In fact, the narrow rooms, often not easily reachable due to the uneven preservation of the ruins, and the short distance between the shelters that cover the entire quarter and the tops of the walls, resulted in a not very dense point cloud with missing information, whereas the presence of a fine sand led to many disturbs during the acquisition phase. This surveying experience seemed to demonstrate that laser scanning is not always the best solution for archaeological areas, due also to its high costs (rental or purchase of the instrument; travel for the operator) not always affordable by an archaeological mission. On one hand, this unsatisfactory result encouraged a deeper evaluation of the methodology of graphical documentation, on the other hand it made clear that the point cloud from digital survey has a huge potential of information as regards the scientific aims of the research and its communication. In particular, since the Quartiere Levi is one of only two cases of buildings surviving up to the third floor in the Aegean world, a digital survey could offer an information potential that goes beyond the limits of traditional survey. Thanks to this type of survey it is in fact possible to easily obtain plans of each floor, as well as sections and elevations of inaccessible rooms, in order to study the construction techniques and the building materials. As mentioned, the Structure from Motion method has been chosen for the acquisition of the site. It offered the best solution so far in the field of low cost and user-friendly survey, providing the expected data. Thanks to the action camera and to the new potentialities of software such as Agisoft Metashape Professional and RealityCapture, it has been possible to realize a scaled, photorealistic and navigable 3D model, with a considerable economy in terms of working time and number of photographs.

\footnotetext{
* Corresponding author
} 


\section{RELATED WORKS}

In recent years, several researches have been developed based on the use of innovative techniques aimed at documenting, safeguarding, enhancing and disseminating the Archaeological Cultural Heritage $(\mathrm{CH})$. These studies aim at preserving the memory of the past and at facilitating the usability of $\mathrm{CH}$, especially when dealing with sites far away or not easily accessible.

In this constantly evolving context, the photogrammetric survey, both terrestrial (conducted by smartphone, traditional lenses, fisheye lenses, 360 cameras, etc.) and aerial (conducted by drone), represents an extremely effective tool for various reasons: in fact, it requires the use of instruments that are often easily available, does not require highly specialized skills and is able to provide a precise and likely reconstruction not only of the geometry, but also of the chromatic data, which is a key element when it comes to digitizing artefacts with a high historical and artistic value (Chiabrando et al, 2017; Altman et al., 2017; Santagati et al., 2017; Costa et al., 2018; Kossieris et al., 2017; Barazzetti et al., 2018).

Research on the photogrammetric survey conducted with fisheye lenses has aroused particular interest in recent years, due to some peculiarities of these instruments, including the possibility of being installed on light and handy cameras and the wide field of view, that allows to significantly reduce the amount of data acquired and to speed up the process of photogrammetric computation. The growing interest for this type of low cost acquisition is confirmed by the availability of various commercial software capable of processing data from cameras with fisheye lenses.

A contribution on these issues has been made by (Barazzetti et al., 2017), whose research highlights the advantages and disadvantages related to the use of fisheye lenses for the realization of photogrammetric models through different commercial software. This research has shown that a fisheye lens is suitable for an accurate metric documentation, especially in the case of limited and narrow spaces.

The same topic is addressed in the survey of the Minguzzi spiral staircase (Perfetti et al., 2017), and in the survey of the Amedeo Spire (Perfetti et al., 2018), both inside the cathedral of Milan. The fundamental objective of these researches is to solve problems of measurement and to accelerate the acquisition and post-processing phases, using (among other things) fisheye lenses for photogrammetric surveying.

In the same context, another research group conducted a photogrammetric survey aimed at reconstructing the morphology of La Sassa Cave, in the municipality of Sonnino (Latina). In this case, the acquisition was made using a Nikon D800E camera with a Nikkor $16 \mathrm{~mm}$ pre-calibrated fisheye lens. In order to obtain a model with reduced deformations, the researchers decided to use previously measured targets. From an archaeological point of view, this technique proved to be extremely valuable for its speed and accuracy (Alessandri et al., 2019).

The experimentations in the field of photogrammetric surveying with fisheye lens are often accompanied by comparisons with other methods (laser scanning and/or photogrammetric survey with various types of cameras and lenses), with the aim of assessing the accuracy of the acquired data and the effectiveness of instruments in relation to the product examined (Mandelli et al., 2017).

Numerous applications have also involved the use of action cams such as GoPro for photographic acquisition; these instruments have lenses with a field of view halfway between the one of fisheye lenses and the one of traditional lenses. These devices play a leading role in low cost surveying methodologies, because they make possible significant savings, not only in economic terms but also in terms of surveying and processing time.

These tools are particularly useful in impervious environments, due to their extreme handling and their ability to withstand extreme conditions (Capra et al., 2015; Helmholz et al., 2016; Neyer et al., 2019).

As regards the use of action cams in the documentation of narrow spaces, a valid research is represented by the survey of Villa di Giulia Felice in Pompeii. It specifically analyses potentialities and limits of the GoPro Hero Black 3, testing three software for image processing (Agisoft PhotoScan, Pix4Dmapper and 3DF Zephyr Aerial) and verifying the results obtained by comparing the $3 \mathrm{D}$ models (Fiorillo et al., 2016).

D. Aiello, G. D'Agostino

\section{CASE STUDY - THE PALACE OF PHAISTOS AND THE SW QUARTER (QUARTIERE LEVI)}

This research focuses on the digital survey of the so-called Quartiere Levi, within the Minoan Palace of Phaistos. The latter, located in Southern Crete (Greece), is one of the most outstanding examples of the Minoan architecture of the II millennium b.C., due to its state of preservation (Fig. 1).

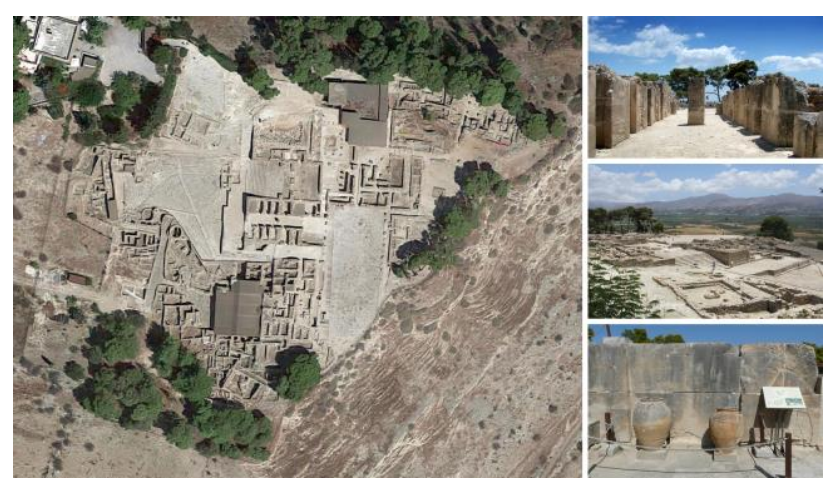

Figure 1. The Palace of Phaistos (D. Aiello)

During its long history (1950-1450 b.C.) the Palace of Phaistos went through two main phases. The historical period analysed in this research is the first one, also known as the protopalatial phase, during which Quartiere Levi was built. The protopalatial phase lasted from the so-called Middle Minoan (MM) IB period (1950 b.C.) to the Middle Minoan IIB period, ending around 1700 b.C. (or 1750 according to a different chronology). At the beginning of this first period, the palace of Phaistos was already a court compound with a complex functional articulation and an autonomous economic activity, and it was the center of an established authority (probably of theocratic character).

Beyond the open spaces, called courts, two main quarters of the first palace survive, linked by the Great Propyleum: The SouthWest Quarter (Fig. 2) and the North-West Storerooms. The latter were used mainly as a storage area, whereas the SouthWest Quarter, excavated by Doro Levi in the years 1950-1966 (and for this reason called Quartiere Levi), had a more complex articulation (Levi, 1976; Militello, 2012).

Thanks to the very good preservation, the articulation of the South-West Quarter is almost clear. The ground floor was centred upon the interaction between an individual of exceptional character and a small group of people, by means of the ritual usage of appreciated stone and clay artefacts. Its circulation pattern was based on three different blocks (Carinci, 2011). The central block was made up by two connected paths, 
the one leading to very small and luxurious rooms, clearly used by one single individual, and the other to the large room LV (characterized by the presence of benches) and especially to the room LXII, much bigger. The goods stored there, but also the large quantity of pottery, were probably used by the inhabitants of the sector for the accomplishment of ritual activities and craft production. On the contrary, the rooms of the upper floor had a domestic character but could also have been working areas. Finally, the function of the rooms of the third floor, in absence of assemblages, is highly uncertain.

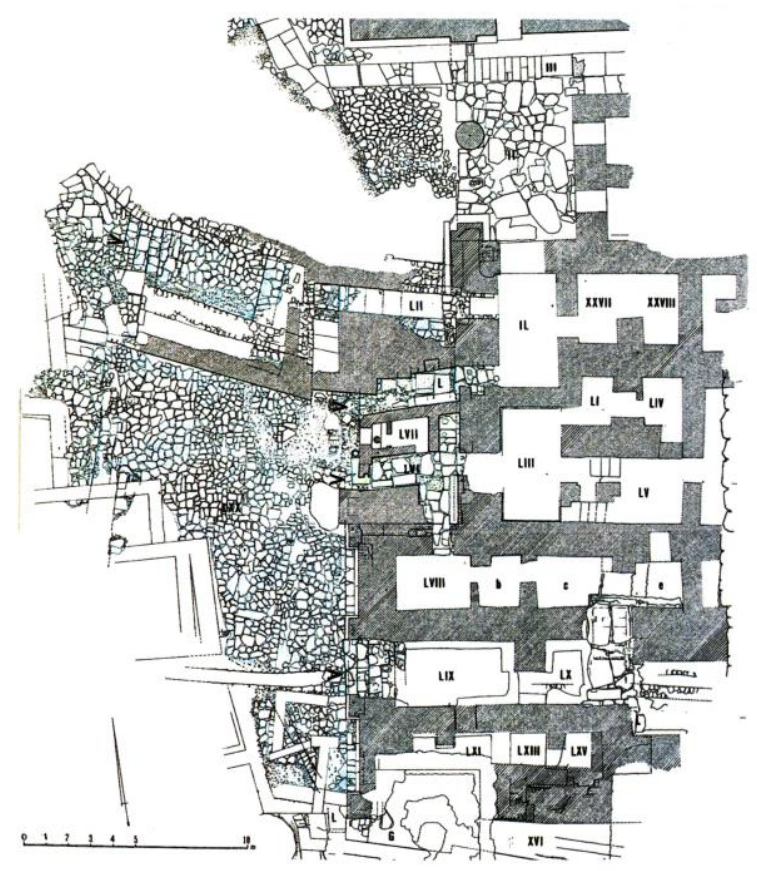

Figure 2. Phaistos. Plan of the South-West Quarter

To sum up, Quartiere Levi was used for many purposes: as a living quarter, with small storage areas, as a working area and as a ritual center. The ritual activity is especially evident in the central area, with rich assemblages of fine decorated Kamares ware, stone vases, stone "kernoi" and ritual paraphernalia. At the same time, evidence for feasting activities has been detected, represented by assemblages of 10-20 fine cups, found along with a twice or three times higher quantity of conical cups, and an equal number of pouring vases, mainly bridge-spouted bowls (rooms IL, XXVII-XXVIII, LIII-LV, CVII).

In the last years of MM IIB, a first seismic event damaged the Palace. During the repairing works, only a part of it was used. In the room LX-LXIV a new wall was built, in a different technique and with large blocks. Many items from other rooms were collected in this area and a new entrance was obtained taking away one of the orthostates in the room LIX. In the Northern area, three rooms were built against the façade, destroying the unity of the architectural planning (Buscemi, 2017).

This phase lasted for a very short period: another earthquake, in fact, destroyed the palace at the end of MM IIB.

After this catastrophic event, the ruins of the First Palace were filled with a purposely made concrete (called Astraki), in order to build the Second Palace. The South-Western sector, built at a lower level, was therefore filled in up to the second floor, thus allowing the ruins to be preserved up to 5-7 meters high.

The First Palace represents therefore a unique example of Prehistoric multi-storey building and, thanks to the rich furniture found inside, an outstanding source of information on Minoan culture.

Nowadays, the direct access to the South-Western Quarter is forbidden to the public, both for visitors' security and ruins protection reasons. For this purpose, the digital survey of the whole quarter was conducted by a research team of archaeologists and engineers from the University of Catania, with the aim of acquiring a detailed 3D documentation of the site.

P. Militello

\section{METHODOLOGY - A COMPARISON BETWEEN DIFFERENT APPROACHES}

\subsection{Digital survey}

4.1.1 2014 survey campaign: In this section, the survey campaign conducted by the research group during 2019 will be described in detail.

As previously mentioned, this experimentation was born with the aim of completing a point cloud acquired in 2014 by an external team to the Humanities Department of the University of Catania. The 2014 survey was mainly devoted to the integration of an already existing photogrammetric model of the entire Palace of Phaistos, obtained through the use of a drone and realized by the University of Salerno. The objective of this aerial survey was to obtain a detailed orthophoto of the entire archaeological site. However, the presence of shelters that cover the South-West Quarter did not allow an exhaustive shooting of this area, generating information gaps in the final orthophoto of the whole complex. In other words, the use of a traditional aerial photography for the documentation of the site failed to fit the scientific goal of the research.

The 2014 survey, therefore, aimed to integrate the covered areas into the aerial photogrammetry, so as to be able to visualize the upper part of the walls, the floors and the main characteristics of the environments (slabs of flooring, benches, stairs).

For the acquisition of the quarter, a Leica ScanStation 2 laser scanner was used (scan resolution: $4 \mathrm{~mm}$ from 0 to $50 \mathrm{~m}$, scanner size: $265 \mathrm{~mm}$ x $370 \mathrm{~mm}$ x $510 \mathrm{~mm}$, weight: $18,5 \mathrm{~kg}$ ). The survey involved the acquisition of 15 scans arranged as shown in figure 3.

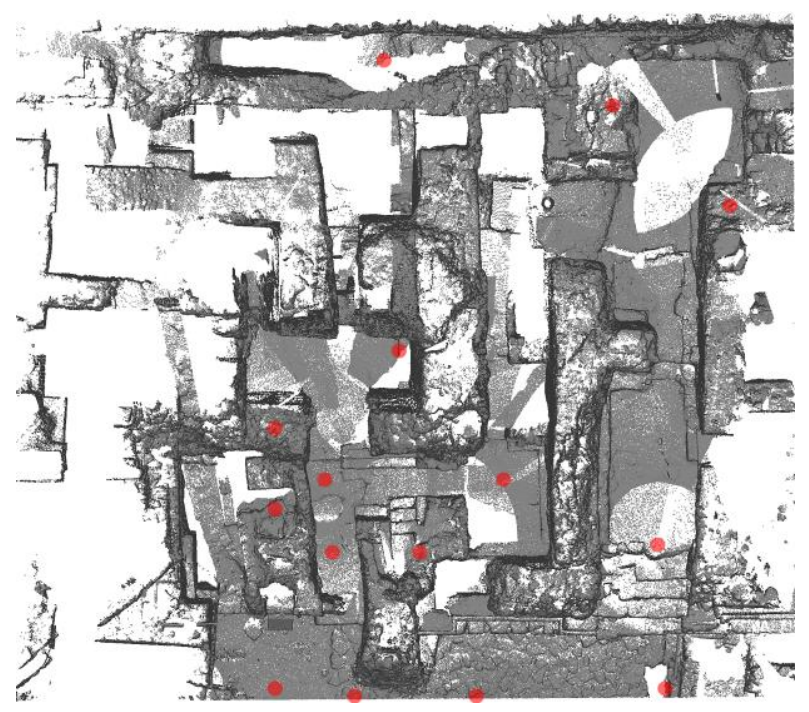

Figure 3. Scans location (G. D'Agostino) 
The result of this survey was a numerical model consisting of about 25 million points.

This model has many gaps and shaded areas due to the excessive size of this equipment compared to the very narrow and inaccessible rooms of the archaeological site (one of the smallest rooms is $1.1 \mathrm{~m}$ wide and $1 \mathrm{~m}$ high). Moreover, the top of the walls was not acquired because of the shelters installed to protect the quarter, placed on average $30 \mathrm{~cm}$ away from the walls. Finally, looking at the laser point cloud, it is possible to see that the color information recorded is extremely poor: this is due to inadequate lighting conditions within the site. In general, the complexity of the structures and of the rooms of Quartiere Levi required a huge amount of work both during the data capture and the postprocessing, still leading to an unsatisfactory result and demonstrating the inefficiency of expensive instruments such as the laser scanner in particular contexts.

F. Buscemi

4.1.2 2019 survey campaign: On the basis of this experience, the 2019 survey campaign was started with the aim of integrating the previously acquired laser scanner point cloud. This time, however, it was decided to experiment with the Structure from Motion methodology, considering that, using photogrammetry, it is possible to reach points out of the laser scanner range and to survey the chromatic data with great precision.

Two different acquisitions were carried out, using two different tools: a GoPro Black Hero 6 action camera and a Canon EOS 70D camera with a traditional lens. The results obtained from the two acquisitions were then compared in order to have information on the metric accuracy of the models obtained.

Action cameras have high quality and very flexible image capture and the radial distortion is normally high. A fundamental parameter to take into account when capturing photos is the field of view (FOV): it is a setting that determines the amount of visible area captured through the camera lens. In GoPro Black Hero 6, Wide FOV captures the largest amount of space, while Linear FOV captures the least. Typically, FOV (Linear $90^{\circ}$, Wide $130^{\circ}$ ) is determined by the amount of space between the lens and image sensor (the further the lens is from the image sensor, the narrower the FOV). The FOV used in this experimentation is the Wide mode, that produces a fisheye appearance, especially at the edges of the scene. Specifically, fisheye lenses have a wider field of view than traditional lenses. For these reasons, they are particularly useful in surveying archaeological sites. This advantage can be crucial to simplify the survey phase: the wide field of view of the GoPro allows to reduce the number of pictures needed to acquire all the site and, as a consequence, to reduce the elaboration time and obtain more manageable data.

As regards the Canon EOS 70D, instead, it is a digital single-lens reflex camera, with a megapixel full frame CMOS sensor $(22,5 \mathrm{x}$ $15 \mathrm{~mm})$, a $6,5 \mu \mathrm{m}$ pixel pitch, an angle of view with a diagonal extent of $74^{\circ} 20^{\prime}-27^{\circ} 50^{\prime}$, and an integrated GPS receiver.

In this experimentation, in order to capture the entire site, 3471 photos were taken with Canon compared to 1872 taken with GoPro.

One of the advantages of using the GoPro for the survey of the archaeological area is its size, its low weight (W: $62.3 \mathrm{~mm}$., $\mathrm{H}$ : $44.9 \mathrm{~mm}$., D: $32.0 \mathrm{~mm}$.; Weight: $118 \mathrm{~g}$.) and its ease of handling, which make it easy to use for acquisitions in confined or narrow spaces. In fact, the small size of the camera and the ability to control the shot through a mobile device (connected via $\mathrm{Wi}-\mathrm{Fi}$ ) allowed to acquire more easily very narrow rooms where voluminous instruments cannot access and to use a telescopic pole for the shooting of not accessible rooms and for the top of the structures, ensuring a complete coverage of the area and avoiding a dangerous or forbidden climbing on the walls. With the Canon camera, instead, it was not possible to acquire the top of the walls and some inaccessible rooms of the upper levels because of its size and weight.

The pictures taken with GoPro, on the other hand, have a lower resolution and are characterized by greater distortion than those taken with the traditional camera.

During the survey phase there was a significant difference in the time spent and the number of shots taken to acquire the entire area. Table 1 summarises some of the results described above, comparing the resolution and number of images taken with the two cameras and the acquisition times.

\begin{tabular}{|l|c|c|}
\hline & GoPro Black Hero 6 & Canon EOS 70D \\
\hline Image resolution & $4000 \times 3000$ & $5472 \times 3648$ \\
Image number & 1872 & 3471 \\
Time of acquisition & $8 \mathrm{~h}$ & $12 \mathrm{~h}$ \\
\hline
\end{tabular}

Table 1. Comparative table between GoPro Black Hero 6 and Canon EOS 70D

G. D'Agostino

\subsection{Data processing}

Both the photographic datasets collected with the two cameras during the survey campaign were processed, at different times, using two photogrammetric software: Agisoft Metashape and Reality Capture. The decision to carry out this double processing for each dataset was aimed at testing the potential and limits of the two software, in order to find the most suitable tool (in terms of precision of the result, ease of use and speed of processing time) to manage the large amount of data acquired in situ and create a sufficiently accurate numerical model of the surveyed area. This comparison was made using an Asus Rog Strix laptop with an i7-4770HQ CPU at $2.80 \mathrm{GHz}$, an NVIDIA Ge-Force GTX 1070 graphics card and 32 GB RAM. The 4 point clouds obtained from this processing allowed to make considerations about the pros and cons that characterize the workflows followed with the two software.

First, the dataset collected with the GoPro was processed within Metashape. During the automatic alignment phase, 1836 images out of 1872 were correctly aligned. Once this step was completed, a dense point cloud of the entire archaeological site was obtained (Fig. 4).

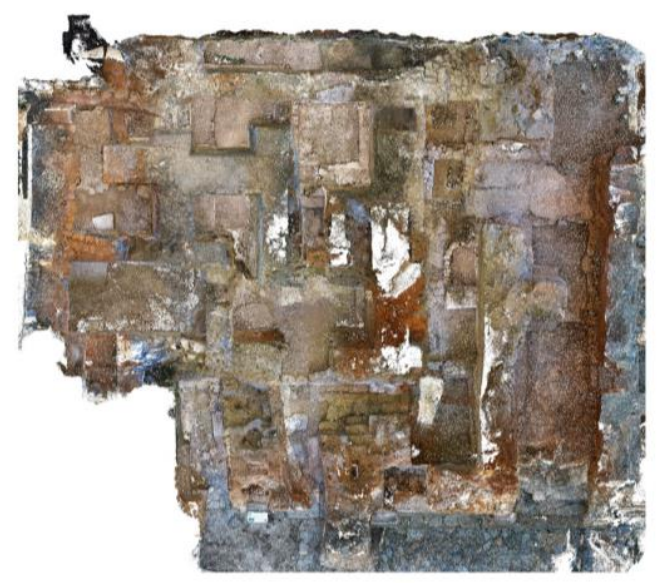

Figure 4. GoPro point cloud (Metashape): top view 
It consists of 160 million points. The creation of the dense cloud (which is always the most expensive operation for the software) did not require excessively long processing times (the 2 days were not exceeded), thanks to the fact that the GoPro dataset consists of a relatively small number of photos.

Subsequently, the photographic dataset collected with the Canon EOS 70D camera was also processed within Metashape. In this case, the processing took much longer (about 4 days), considering that, to cover the entire site, it was necessary to take a much larger number of photos than with the GoPro. At the end of the processing, 3454 out of 3471 photos were correctly aligned, generating a point cloud of about 490 million points. The point cloud obtained, of course, consists of a higher number of points than the GoPro dense cloud, despite the parameters (depth filter and quality) set at the beginning of the processing were the same.

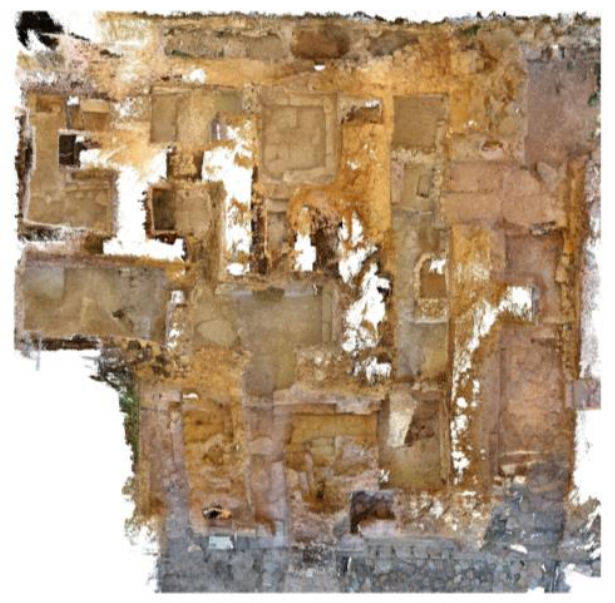

Figure 5. Canon point cloud (Metashape): top view

Both point clouds were finally georeferenced to the laser scanner point cloud. The referencing was done on Metashape, assigning to 10 points of each dense cloud the coordinates of their counterparts, extrapolated (using Cyclone) from the laser scanner point cloud.

At the same time, both photographic datasets were processed within RealityCapture. Also in this case, the software automatically led to the creation of two point clouds. Specifically, starting from the GoPro dataset, the software was able to automatically align 1697 images out of 1872 , obtaining a point cloud of about 120 million points (Fig. 6). Using the Canon dataset, however, the software was able to automatically align 3125 images out of 3471 , obtaining a point cloud of about 450 million points. Similarly to the numerical models obtained on Metashape, these two clouds were also aligned with the laser point cloud.

At this point, it was possible to compare the results of the two workflows, identifying strengths and weaknesses.

A first significant strength of RealityCapture concerns the processing phase, which took only some hours, while took more than 3 days on Metashape. RealityCapture also allows to process the dense cloud and mesh simultaneously, helping to make the workflow faster and easier.

On the other hand, RealityCapture reveals a weakness in the impossibility of manipulating the imported photos. In Metashape, instead, it is possible to hide the disturbing areas or the defects in brightness of any image by using masks before building the mesh. To get the same result in RealityCapture, it is previously necessary to modify the pictures on other software.

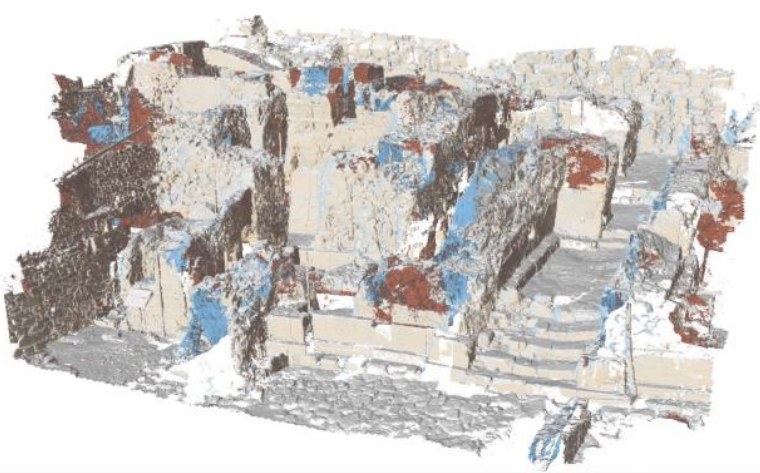

Figure 6. GoPro point cloud (RealityCapture): perspective view

From this analysis, it was also found that Reality Capture, despite being able to produce in a relatively short time both the point cloud and the mesh, allows to export the point cloud in only in xyz format, that is not supported by many software for the management of point clouds.

There is another limit of RealityCapture, which occurs especially when the photographic dataset consists of a large number of photos: in these cases, during the automatic alignment, the software tends not to align all the photos together, generating different components that contain portions of point cloud separated from each other, all with different scale and orientation. When this happens, it is necessary to act manually, identifying the control points in common between individual frames of the different components and repeating the alignment. This operation is very complex and takes a long time, considering the difficulty in finding the exact position of the homologous points on the different images.

This comparison, in short, has allowed the researchers to understand that, when dealing with such complex objects (such as archaeological sites, characterized by highly irregular surfaces and extremely complex volumes), RealityCapture is not always the most effective tool.

\section{Aiello}

\subsection{Comparisons with the laser scanner point cloud}

Considering that the metric information acquired by the laser scanner is absolutely the most accurate, it was decided to evaluate the precision of the models obtained from the photogrammetry of 2019 (i.e. the two clouds created with Metashape and the two clouds created with RealityCapture) comparing them with the laser scanner point cloud.

As regards the two dense georeferenced point clouds obtained on Metashape, they were exported in .e57 format and imported on CloudCompar (a software for the management of point clouds), within which the degree of adherence of the two photogrammetric clouds with respect to the laser cloud (used as a target) was then verified.

From the overlap between the laser scanner point cloud and the point cloud obtained with the GoPro the following graph was obtained (Fig. 7).

It can be seen that this point cloud shows in many areas a significant average overall deviation (about $2.5 \mathrm{~cm}$ ) from the laser cloud. The red parts, as well as most of the orange, yellow 
and green parts, are not actually taken into account, because they are related to portions of the photogrammetric cloud that do not exist in the laser cloud (because the laser was unable to acquire them); in these cases, the color difference (red, orange, yellow or green) is due to the fact that, in areas where there are points surveyed only with the camera, the software evaluates in any case the distance between the photogrammetric cloud and the nearest points of the target cloud.
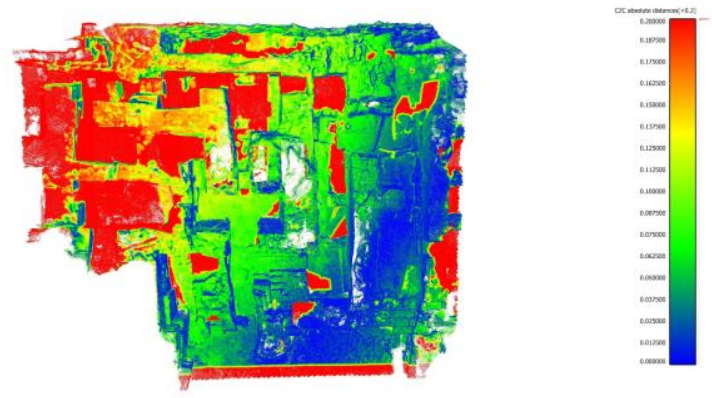

Figure 7. Comparison between the laser scanner point cloud and the GoPro point cloud built in Metashape

As regards the second comparison, the overlap between the target point cloud and the cloud obtained with the traditional camera shows a much lower average error. Most of the area surveyed with both instruments (laser scanner and Canon camera) is colored in blue: this means that the deviation between the two clouds is almost everywhere far less than $1 \mathrm{~cm}$. However, it is clear that the area surveyed by the Canon camera is smaller than the one acquired with the GoPro: this lower coverage is due to the fact that the GoPro is much lighter and easier to handle than the traditional camera, so it was possible to use it in points that the Canon camera was not able to reach (Fig. 8).
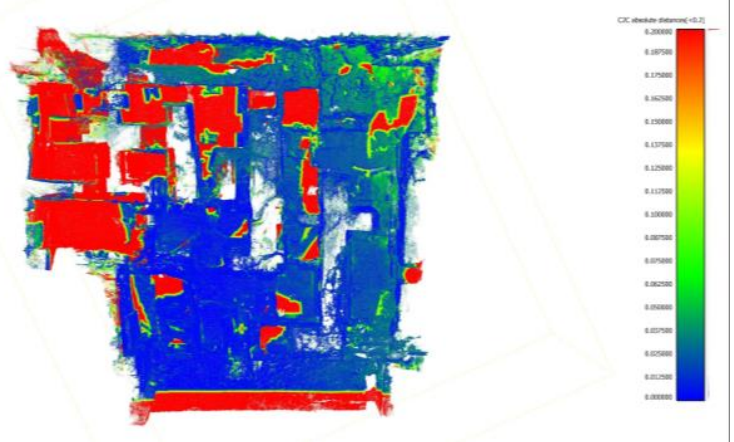

Figure 8. Comparison between the laser scanner point cloud and the Canon point cloud built in Metashape

These data are very interesting because they allow to understand the pros and cons of the two photogrammetry devices.

The fisheye lens provided a more complete, simpler, more manageable, but more inaccurate point cloud. The traditional lens, instead, allowed to generate a point cloud characterized by a lower error and a more precise chromatic data, but with a huge number of points and a greater missing information (although the acquired dataset was almost three times larger).

The same comparison was made between the target cloud and the two photogrammetric clouds obtained within RealityCapture. The overlap with the GoPro cloud has obtained the result showed in Fig. 9.
As can be seen, the average deviation is quite low almost everywhere. However, the photogrammetric cloud has many gaps and is very noisy.
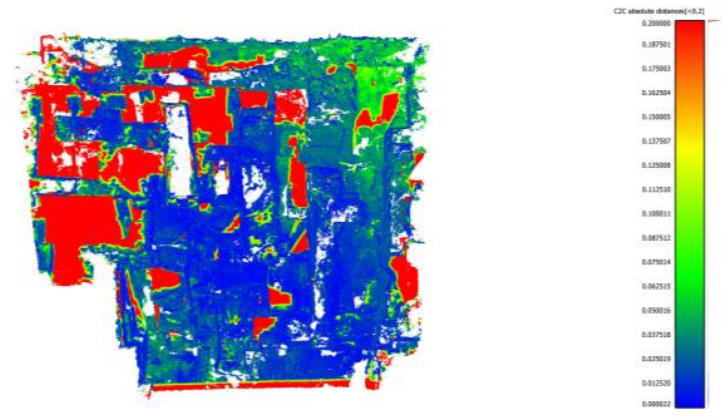

Figure 9. Comparison between the laser scanner point cloud and the GoPro point cloud built in RealityCapture

Instead, the point cloud obtained within RealityCapture with the Canon dataset is characterized by an accuracy very similar to the one of the point cloud obtained within Metashape. Also in this case, however, the cloud has gaps due to the lack of alignment of some photos.

Summing up these comparisons, it is clear that, from a qualitative point of view, the Canon cloud is more precise both in the reconstruction of the volumes and in the restitution of the chromatic data, but the GoPro cloud is more complete, because the instrument used has been able to survey points not reachable with the Canon (nor with a bulky laser scanner, as demonstrated by the survey attempt in 2014). In conclusion, considering both the type of environment (characterized by extremely complex and irregular geometries) and the purpose of the survey (archaeological study of the spatiality of the architectural complex and future virtual reconstruction of the site), the most effective approach was the photogrammetric survey conducted by GoPro, whose limits and inaccuracies are substantially negligible for this research.

With respect to the software, Metashape seems to be more effective than RealityCapture: in fact, despite the long processing time, the software tends to automatically align a larger number of photos and also generates point clouds more precise and less noisy. It should be noted that the outcome of this experimentation (i.e. the choice of the model obtained with GoPro and processed within Metashape) was by no means predictable: each surveyed artefact has in fact unique peculiarities (irregular surfaces, narrow spaces, particular chromatic characteristics, particular natural/artificial lighting conditions, obstacles, etc.), which, especially when they are variously combined together, do not always make it possible to understand in advance what could be the most effective tools for surveying and processing data. It is therefore essential to evaluate every strategy, device and software on a case-by-case basis.

D. Aiello

\subsection{Graphic elaborations}

The Quartiere Levi is an extremely important case study, for its complex spatial articulation and rich stratigraphy, which allows to clearly read the traces of different construction phases. The 2019 experiment, which involved several professionals (archaeologists and engineers) in the field of cultural heritage, allowed to obtain a complete scientific documentation of the site, thanks to which it was possible to update and revise the 
first representations in plan and elevation produced by Raffaele Oliva, who was a designer of Doro Levi since the excavation campaign of 1950 and to whom we owe all the drawings published on (Levi, 1976).

The updating of the old drawings was possible thanks to new plans and sections extracted from the point cloud obtained with the GoPro. The latter contains a quantity of accurate information that the old direct survey had not allowed to acquire immediately, because of the presence of many inaccessible points where it was impossible to take measurements manually. Precisely for this reason, in the $2 \mathrm{D}$ drawings obtained from the old survey, some areas of the complex had been indirectly reconstructed, increasing the load of inaccuracies.

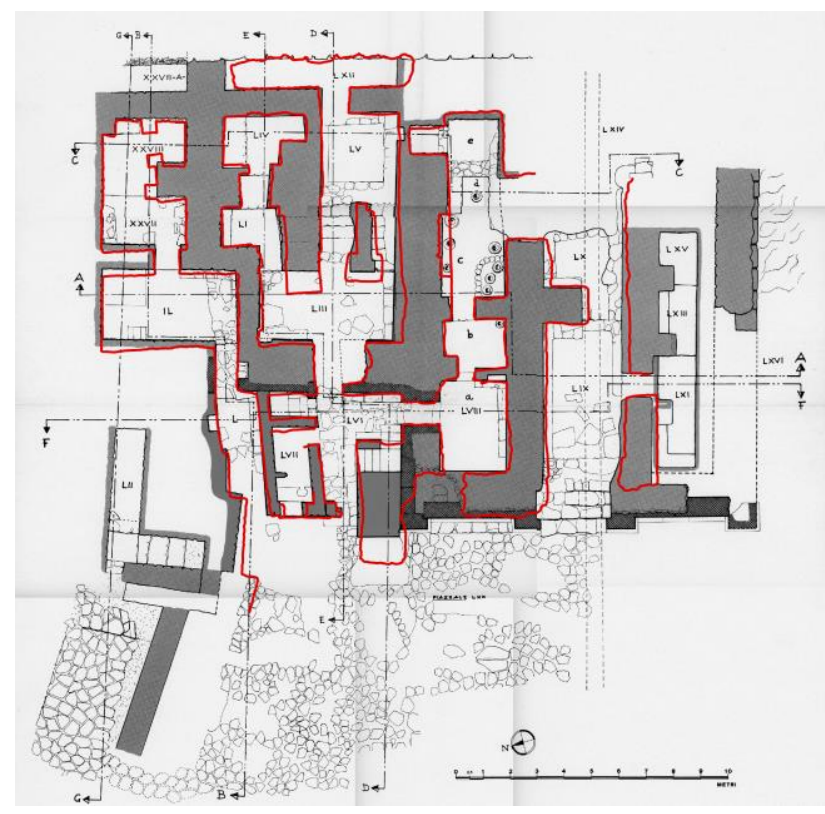

Figure 10. Overlap between the old plan and the one obtained from the photogrammetric model (red line)
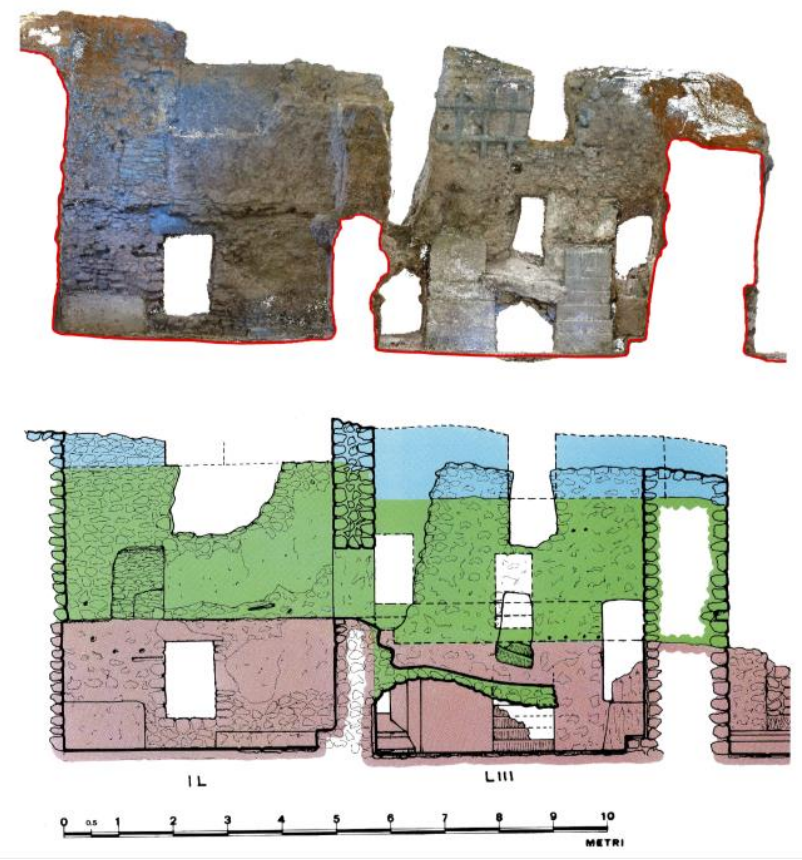

Figure 11. Detail of the section A-A
Most of these inaccessible areas were acquired with the tools used in 2019, which resulted in a sufficiently accurate threedimensional model of the entire site, which revealed many deviations from previous representations. The advantage of the first results of the 2019 survey lies above all in the presence of information not only planimetric but also altimetric, which would not have been possible to detect with traditional measurement techniques. From the figure 10 and 11, for example, it is possible to see, along the walls, various deformations in elevation that in the old survey had not been observed.

Similarly, it was possible to establish with greater precision the position of some portions of the masonry, which led to significant changes in the vertical sections.

In this context, the 2019 experiment was a significant starting point for a reflection on methodologies of archaeological survey in a historical perspective, aimed at assessing the effectiveness of new acquisition technologies developed in recent decades.

G. D’Agostino

\section{CONCLUSION AND FUTURE RESEARCH}

This research (enriched by the interdisciplinary contribution of professionals in the field of archaeology and architecture) has tried to demonstrate the efficiency of the low-cost tools for the documentation of archaeological sites, encouraging in-depth reflection among specialists, primarily about the reuse of data from different documentation campaigns of cultural heritage. The large amount of data obtained from a survey is always an indispensable resource, even when the information is acquired with different techniques and at different times. Incomplete information is also useful when it is possible to update and integrate it with more advanced technologies and methods. Another awareness concerns the importance of the experimentation carried out through the combined use of different tools and strategies, with the aim of finding the most effective way to document sites with unique characteristics, rich in heterogeneity and stratifications. This theme is particularly relevant in the archaeological field, where we often have to deal with places characterized by complex geometries, inaccessible spaces, different materials and construction techniques, which require survey campaigns adapted to the context.

In the specific case of Quartiere Levi, the potentialities of the digital survey have a special political and cross-cultural interest in the relationship between the archaeological missions and the guest country where they work. In fact, thanks to the data acquired through the survey, it is possible to propose innovative experiences of fruition, communication and enhancement of cultural heritage: in this way, starting from the simple documentation, it would be possible, for example, to provide the local museum with 3D printed models or virtual/augmented reality experiences, that would constitute a strong encouragement for the cooperation in the enhancement of the archaeological site.

As mentioned, Quartiere Levi is currently closed to the public and needs specific permissions also for the access of specialist scholars, so its virtual reconstruction could constitute a good opportunity to know this extraordinary complex and an effective tool for its preservation, protecting some delicate materials (such as the gypsum slabs of the floors) from a massive use. In the future, the research group will work on the development of a serious game, a smart, educational and appealing tool for promoting the interest of the wider public and the knowledge of archaeological basics. 


\section{ACKNOWLEDGEMENTS}

This work has been partially financed by the University of Catania within the project "Piano della Ricerca Dipartimentale 20162018" of the Department of Civil Engineering and Architecture of University of Catania and the Ministero Affari Esteri.

Furthermore, the research group would like to thank the Archaeological Service - Herakleion and the Scuola Archeologica Italiana di Atene.

\section{REFERENCES}

Alessandri, L., Baiocchi, V., Del Pizzo, S., Rolfo, M. F., and Troisi, S., 2019: Photogrammetric survey with fisheye lens for the characterization of the La Sassa cave. Int. Arch. Photogramm. Remote Sens. Spatial Inf. Sci., XLII-2-W9-252019.

Altman, S., Xiao, W., and Grayson, B., 2017: Evaluation of low-cost terrestrial photogrammetry for $3 \mathrm{D}$ reconstruction of complex buildings. Int. Arch. Photogramm. Remote Sens. Spatial Inf. Sci., IV-2/W4. 199-206. 10.5194/isprs-annals-IV-2W4-199-2017.

Barazzetti, L., Previtali, M., and Roncoroni, F., 2017: Fisheye lenses for 3d modeling: evaluations and considerations. Int. Arch. Photogramm. Remote Sens. Spatial Inf. Sci., Nafplio, Greece, Vol. XLII-2/W3, pp. 79-84, doi:10.5194/isprs-archivesXLII-2- W3-79-2017.

Barazzetti, L., Previtali, M., and Roncoroni, F., 2018: Can we use low-cost 360 degree cameras to create accurate $3 \mathrm{~d}$ models?. Int. Arch. Photogramm. Remote Sens. Spatial Inf. Sci., XLII-2, 69-75, https://doi.org/10.5194/isprs-archives-XLII-2-69-2018.

Buscemi, F., 2017: Festòs 2014: l'attività di rilievo digitale, in: Militello, P.M., and Buscemi, F., L'attività dell'università di Catania a festòs nel 2013-2014, asaa xciii, serie iii, 15, 2015 (2017), 293-302.

Costa, E., Guerra, F., and Vernier, P., 2018: Self-assembled rov and photogrammetric surveys with low cost techniques, Int. Arch. Photogramm. Remote Sens. Spatial Inf. Sci., XLII-2, 275279, https://doi.org/10.5194/isprs-archives-XLII-2-275-2018.

Capra, A., Dubbini, M., Bertacchini, E., Castagnetti, C., and Mancini, F., 2015: 3d reconstruction of an underwater archaelogical site: comparison between low cost cameras, Int. Arch. Photogramm. Remote Sens. Spatial Inf. Sci., XL-5/W5, 67-72, https://doi.org/10.5194/isprsarchives-XL-5-W5-672015.

Carinci, F., 2011: Per una rilettura «funzionale» dell'ala sudoccidentale del palazzo di festos: il caso dei vani ilXXVII/XVIII, in Creta Antica, 12, 17-125.

Chiabrando, F., D'Andria, F., Sammartano, G., and Spano, A., 2017: UAV photogrammetry for archaeological site survey. 3D models at the Hierapolis in Phrygia (Turkey). Virtual Archaeology Review. 9. 10.4995/var.2018.5958.

Fiorillo F., Limongiello, M., and Fernández-Palacios, B.J., 2016: Testing GoPro for 3D model reconstruction in narrow spaces, IMEKO-ACTA-05 (2016)-02-09.
Helmholz, P., Long, J., Munsie, T., and Belton, D. 2016: Accuracy assessment of go pro hero 3 (black) camera in underwater environment, Int. Arch. Photogramm. Remote Sens. Spatial Inf. Sci., XLI-B5, 477-483, https://doi.org/10.5194/isprs-archives-XLI-B5-477-2016.

Kossieris, S., Kourounioti, O., Agrafiotis, P., and Georgopoulos, A., 2017: Developing a low-cost system for 3D data acquisition, Int. Arch. Photogramm. Remote Sens. Spatial Inf. Sci., XLII-2/W8, 119-126, https://doi.org/10.5194/isprsarchives-XLII-2-W8-119-2017.

Levi, D., 1976: Festòs e la civiltà minoica I. Roma: Edizioni dell'Ateneo. Incunabula Graeca 50.

Mandelli, A., Fassi, F., Perfetti, L. and Polari, C., 2017: Testing different survey techniques to model architectonic narrow spaces, International Archives of the Photogrammetry, Remote Sensing and Spatial Information Sciences, XLII-2/W5, 505511, 10.5194/isprs-archives-XLII-2-W5-505-2017.

Militello, P., 2012: Emerging authority. A functional analysis of the MM II settlement of Festòs, in J.Driessen, I,. Schoep, P,. Tomkins, (eds), Back to the Beginning. Reassessing social, economic and political Complexity in the Early and Middle Bronze Age on Crete, Int. Conference, Leuven 1-2 february 2008, Oxford: Oxbow books 2012, 236-272. 978-1-84217421-9.

Neyer, F., Nocerino, E., and Gruen, A., 2019: Image quality improvements in low-cost underwater photogrammetry, Int. Arch. Photogramm. Remote Sens. Spatial Inf. Sci., XLII2/W10, 135-142, https://doi.org/10.5194/isprs-archives-XLII-2W10-135-2019.

Perfetti, L., Polari, C., and Fassi, F., 2017: Fisheye photogrammetry: tests and methodologies for the survey of narrow spaces, Int. Arch. Photogramm. Remote Sens. Spatial Inf. Sci., XLII-2/W3, 573-580, https://doi.org/10.5194/isprsarchives-XLII-2-W3-573-2017.

Perfetti, L., Polari, C., and Fassi, F., 2018: Fisheye multicamera system calibration for surveying narrow and complex architectures. Int. Arch. Photogramm. Remote Sens. Spatial Inf. Sci., XLII-2. 877-883. 10.5194/isprs-archives-XLII-2-8772018.

Santagati, C., Lo Turco, M., Bocconcino, M. M., Donato, V., and Galizia, M., 2017: 3D models for all: low-cost acquisition through mobile devices in comparison with image based techniques. potentialities and weaknesses in cultural heritage domain, Int. Arch. Photogramm. Remote Sens. Spatial Inf. Sci., XLII-2/W8, 221-228, https://doi.org/10.5194/isprs-archivesXLII-2-W8-221-2017. 